\title{
A regulação no setor de saneamento: comparação entre França, Inglaterra e Brasil
}

\author{
Marcelo Bruto da Costa Correia
}

\section{Introdução}

A regulação de serviços de utilidade pública ocupou espaço destacado nas reformas da administração pública das últimas décadas, sendo exemplares os casos de telecomunicações e energia, setores cuja exploração foi delegada à iniciativa privada em vários países, desafiando-se o caráter de monopólio natural dos serviços pela introdução de mecanismos competitivos.

Entre os setores de utilidade pública, entretanto, o serviços de abastecimento de água e esgotamento sanitário foram dos poucos que resistiram às inovações regulatórias; salvo raras exceções, como a Inglaterra, a França e o Chile (Parlatore, 2000), a participação privada não se estendeu aos graus de envolvimento de outros setores e tampouco lograram êxito mecanismos que procurassem reproduzir, por meio da regulação, um ambiente competitivo no setor. Não por acaso, há quem indague se estamos diante do último monopólio natural em sentido estrito (SeppäLlä, Hukka E Katko, 2001). 
No Brasil, a despeito de já se passarem mais de 15 anos do fim formal do Plano Nacional de Saneamento - Planasa, modelo de repartição de atribuições e financiamento implantado pelo regime militar na década de 70, mais de $80 \%$ da população nacional permanece atendida por concessionárias estaduais de saneamento básico que exploram os serviços sob, praticamente, o mesmo desenho institucional do Planasa.

Nos últimos anos, contudo, inovações institucionais como a Lei das Parcerias Público-Privadas (lei federal no 11.074/ 2004), a Lei dos Consórcios Públicos (lei federal $\left.n^{\circ} 11.107 / 2005\right)$ e, finalmente, a Lei do Saneamento Básico (lei federal $n^{\circ}$ 11.445/2007), aparentemente abriram uma janela de oportunidade para que os entes federados se reorganizem em novos arranjos institucionais que superem a inércia provocada pelo conflito federativo entre estados e municípios sobre a titularidade dos serviços em regiões metropolitanas. Esta última lei, em especial, foi aprovada após 15 anos de infrutífera tramitação de diversos projetos de lei que procuravam dar um novo desenho à regulação de saneamento no País.

Ao examinarmos a experiência de outros países, em especial daqueles que procuraram atrair a iniciativa privada para investir no setor, como é o caso da França e Inglaterra, o fato inarredável é que superar o impasse da competência constitucional é apenas o início do desafio: entre os serviços de utilidade pública, a regulação do saneamento é das mais complexas, dadas as características político-institucionais e tecnológicas que marcam o setor.

França e Inglaterra apresentam modelos regulatórios com ricas experiências históricas. A primeira, por seu caráter descentralizado, com protagonismo das autoridades locais; a segunda, por resultar de um ambicioso processo de privatização com criação de novas regras e entidades que tinham por objetivo reproduzir por meio da regulação condições de mercado no setor.

O presente trabalho procurará descrever os aspectos mais marcantes da regulação do saneamento básico na França, na Inglaterra e no Brasil, identificando as principais dificuldades enfrentadas por esses países para prover os referidos serviços às suas populações.

O artigo é composto de seis seções, incluindo esta introdução. A segunda seção identifica as características do setor de saneamento básico que delimitam os desafios para a regulação. As terceira, quarta e quinta seções tratam da regulação, respectivamente, na França, na Inglaterra e no Brasil. Na última seção, concluímos resumindo as diferenças e dificuldades mais marcantes entre os modelos regulatórios e destacando o desafio brasileiro: superar de forma descentralizada a sub-regulação atual em prol de uma regulação efetiva.

\section{Aspectos gerais da regulação do saneamento}

O baixo dinamismo tecnológico do setor de saneamento o distingue de outros setores, como telecomunicações e energia, por limitar consideravelmente a possibilidade de introdução de mecanismos de competição. Como explicam Turolla, Anker e Faria (2004), um setor pode deixar de ser um monopólio natural quando as atividades associadas atingem a maturidade e se tornam completas em termos de tecnologia e saturação de mercado, segregando-se diferentes segmentos de atividades que se convertem em competitivos. O problema, afirmam, é que o 
saneamento ainda não chegou a esse estágio ${ }^{1}$. É prematuro afirmar que outros setores, como telecomunicações e energia, superaram as características de monopólio natural. Mas é certo que, especialmente no primeiro caso, a interconexão permitiu a introdução de segmentos de atividades bastante competitivos.

Não é somente a estagnação tecnológica que torna o setor de saneamento ainda mais complicado. Os ganhos de escala, no setor de saneamento, se combinam com as economias de aglomeração (CORRALES, 1998). O serviço só se torna economicamente viável a partir de um determinado número de consumidores, o que é especialmente delicado quando constatamos que, em quase todo o mundo, água e esgoto são providos por autoridades locais, com jurisdição em áreas pequenas ${ }^{2}$.

O resultado é que, para as regiões sem aglomeração suficiente, subsídios são necessários para viabilizar a exploração dos serviços. A isso se somam externalidades positivas e negativas relacionadas à prestação dos serviços, referentes ao meio ambiente, à saúde pública e ao uso de um recurso escasso (água), resultando numa regulação que não é apenas econômica, mas envolve aspectos que exigem, em regra, a presença de mais de um regulador.

Enfim, outra característica é histórica e política. Tradicionalmente, autoridades locais assumiram a incumbência pela prestação dos referidos serviços, de forma que é rara a possibilidade, como ocorreu no caso inglês, de que o governo central implemente uma reforma ambiciosa no setor.

\section{A regulação do saneamento na França}

Dos modelos regulatórios a que nos reportamos no presente trabalho, é o francês que encontra suas mais longínquas origens, de que é ilustrativo o fato de que são francesas as maiores multinacionais do setor de saneamento no mundo, como a Lyonnaise des Eaux e a Générale des Eaux.

De fato, como expõe Reynaud (2007), o mais antigo relato de participação privada no setor de saneamento na França data de 1776, quando a cidade de Paris delegou por 15 anos para os Sieurs Perrier a exploração dos serviços de abastecimento de

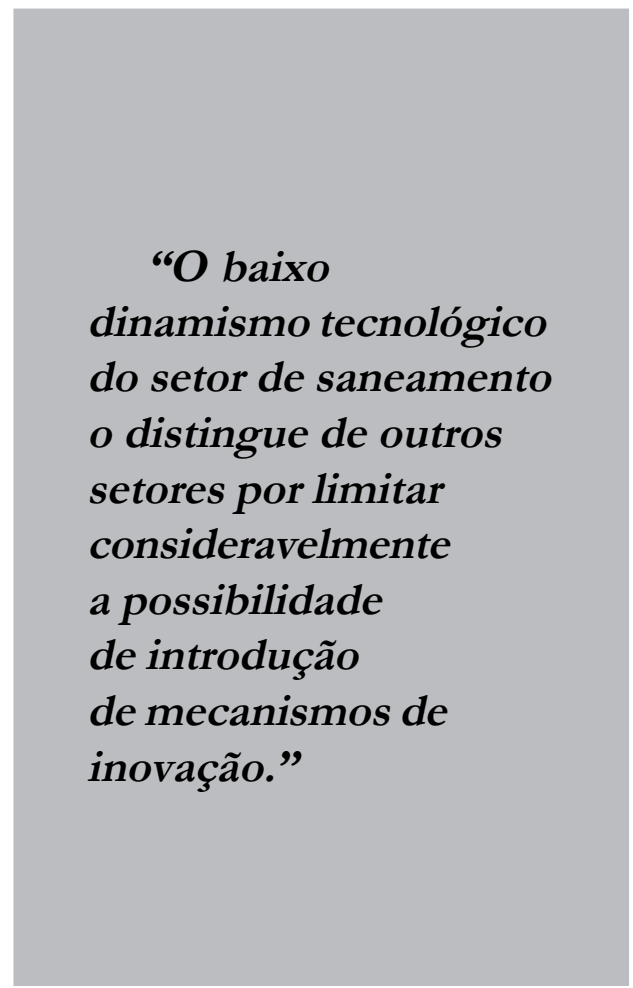

água em sua jurisdição. Desde então as comunidades locais têm sido responsáveis pela organização dos serviços de água e esgoto no país, responsabilidade que veio a ser juridicamente reconhecida pelo Conseil d'Etat ao fim do século XIX. Essa marcante descentralização do modelo francês de regulação é representada pela existência, em 2003, de 29.300 serviços de saneamento no país entre 36.679 comunidades 
locais, sendo 14.900 unidades de serviços de abastecimento de água e 14.400 de serviços de esgotamento sanitário (idem).

Embora as autoridades locais francesas tenham grande discricionariedade na organização dos serviços, ainda assim têm de observar os parâmetros regulatórios regionais, nacionais e continentais. Primeiramente, a União Européia edita na esfera continental várias provisões vinculantes para os seus membros, abrangendo a proteção da qualidade da água e o controle da poluição - normas cujo rigor aumentou especialmente a partir da década de $90 .^{3}$

Em âmbito nacional, mesmo após o movimento de descentralização francês do início da década de 80 (Pollitt e BOUCKAERT, 2000), preservam-se centralizadas as funções essenciais de garantir o cumprimento das regras nacionais de delegação de serviços (Loi Sapin, de 1993), especialmente a legalidade dos processos de licitação, a saúde pública, o controle de poluição, a segurança, o cumprimento de standards técnicos e o controle e gestão do uso dos recursos hídricos por meio das agências de água responsáveis pela regulação das seis bacias hidrográficas francesas ${ }^{4}$. Estas últimas, inclusive, cobram tarifas (redevances) dos operadores de água, subsidiando o tratamento de efluentes (REYNAUd, 2007).

Dessas atividades participam os ministérios do Meio Ambiente e da Indústria (qualidade da água distribuída e dos esgotos tratados), as diretorias departamentais da Ação Sanitária e Social (credenciamento de laboratórios para ações de vigilância da qualidade da água), as "agências financeiras de bacias" (gestão dos recursos hídricos), as câmaras regionais de Contas (fiscalização das contas das empresas delegatárias) e juízes administrativos (julgamento de denúncias sobre processos de contratação) (Parlatore, 2000).
Há de se destacar, ainda, que o Código dos Municípios criou regras sobre as contas das empresas prestadoras e sua publicidade, exigiu a instituição de comissões de Controle para os casos em que a receita de funcionamento supere 500 mil francos, exigiu a presença de parlamentares da oposição nas comissões de concorrência pública e a criação de comissão consultiva dos serviços delegados, com participação obrigatória de representantes de usuários, nos municípios com mais de 3.500 habitantes (Parlatore, 2000).

Respeitadas as regras acima descritas ${ }^{5}$, as autoridades locais têm ampla discricionariedade para organizar a prestação dos serviços públicos, o que inclui a escolha da forma de prestação dos serviços, a definição das tarifas, o estabelecimento das regras para a entrada e a saída dos prestadores. Essa liberdade se manifesta, de forma bastante evidente, na escolha do prestador, que pode ser interno ou externo à administração.

No primeiro caso, a autoridade local pode adotar o que se chama direct management, outorgando a um órgão de sua administração direta o dever de prestar os serviços; pode instituir um departamento com autonomia orçamentária segregada da administração direta para dirigir os serviços, o que se denomina régie autonome; ou pode, ainda, criar uma société d'économie mixte locale, uma empresa estatal sob seu controle, mas de natureza privada e, portanto, com maior flexibilidade, atribuindo-lhe a missão de prestar os serviços (HuET e SAussier, 2003).

A prestação interna - através de órgão, departamento autônomo ou empresa estatal - é minoritária na França, onde 80\% do mercado é controlado por prestadores privados, com forte concentração empresarial em multinacionais do porte $\mathrm{da}$ Lyonnaise des Eaux e da Générale des Eaux. 
Contudo, mesmo a forma de prestação privada é bastante variável, havendo inúmeros instrumentos jurídicos que se distinguem de acordo com o arco de responsabilidades e riscos transferidos do Poder Público para o operador privado.

A contratação mais aproximada da prestação interna é a gérance, na qual a operadora recebe uma contraprestação fixa pelos seus préstimos. Dessa contratação com baixo grau de envolvimento do particular se diferenciam as outras modalidades enquadradas no gênero de delegated management contracts.

A primeira espécie desse gênero é a régie intéressée, cuja diferença em relação à gérance consiste na remuneração do contratado, desta feita dependente de seu desempenho.

A segunda, que é a mais disseminada entre as autoridades locais francesas, é a affermage, caracterizada pelo compartilhamento de investimentos entre os parceiros público e privado - permanecendo públicos os investimentos mais importantes -, sendo o segundo remunerado não mais pelo Poder Público contratante, mas pelos usuários dos serviços.

Enfim, a modalidade com maior grau de envolvimento privado é a concessão, em que a concessionária assume um alto grau de risco e a responsabilidade pelos investimentos durante o contrato, que apenas são revertidos para o Poder Público ao término da concessão.

A descentralização e a liberdade para escolher diferentes arranjos voltados à prestação dos serviços públicos são características marcantes do modelo francês, que foram acompanhadas por Portugal e Espanha (Huet e SAussier, 2003), a não ser por uma outra peculiaridade do modelo francês: o caráter intuitu personae das contratações. Segundo esses autores, embora na gérance não haja grandes diferenças no processo licitatório - a autoridade pública seleciona o contratado de acordo com critérios objetivos previamente definidos -, nas demais modalidades contratuais (régie interessée, affermage e concessão), após ultrapassada a etapa inicial em que é selecionado objetivamente um certo número de interessados que preenchem os requisitos básicos exigidos pela autoridade local, segue-se uma fase de negociação com ampla liberdade para a autoridade pública escolher o contratado de acordo com os critérios objetivos e subjetivos que melhor lhe aprouverem.

Essa discricionariedade das autoridades locais, para os autores, demarca as principais características do modelo francês de regulação, instrumentalizado por quatro tipos de liberdade: a de organizar os serviços sem intervenções, exceto na regulação técnica (ambiental, recursos hídricos e standards de qualidade, processo licitatório), de um ente regulador nacional; a de escolher entre prestar os serviços diretamente ou mediante a contratação de um operador privado; a de lançar mão do arranjo contratual que melhor lhe aprouver; e a de decidir o parceiro que pretenda contratar sem estar restrito a critérios objetivos e previamente definidos, o que se denomina o "princípio intuitu personae".

É evidente que, num tal modelo em que a regulação econômica é determinada pelas autoridades locais de acordo com o modo de prestação que for por elas definido, as regras que estabelecem as obrigações e os direitos de cada parte são delimitadas pelo contrato - daí por que a denominação "regulação por contrato" ou "regulação por processos" para o modelo francês, conceituada por Corrales (1998).

A despeito da longa tradição do modelo francês de regulação por contratos, não é 
incomum a crítica à liberdade concedida às autoridades públicas locais para a seleção dos contratados, cujos efeitos deletérios seriam demonstrados pela grande concentração de mercado entre poucos prestadores, como as já citadas multinacionais francesas, além das acusações de colusão entre os prestadores ${ }^{7}$.

\section{A regulação do saneamento na Inglaterra $^{8}$}

O atual modelo regulatório inglês encontra suas origens nas reformas da administração pública da década de 80 , em cujo contexto a Inglaterra foi uma das pioneiras na introdução de inovações gerenciais. Uma das vertentes da reforma inglesa foi a separação entre "compradores" e "prestadores" de serviços públicos, abrindo-se a oportunidade para a participação privada na provisão de serviços públicos através da compulsory competitive tendering, que exigia das autoridades locais que realizassem concorrência para a prestação de serviços antes monopolizados pelos órgãos estatais (POLlitt e Bouckaert, 2000).

Foi nesse ambiente que, ao final da década de 90, quando a Inglaterra já privatizara empresas estatais que atuavam na produção de bens e serviços para o mercado 9 e introduzira a compulsory competitive tendering, as empresas estatais que atuavam no setor de abastecimento de água e esgotamento sanitário foram privatizadas, sendo instituído um novo marco regulatório para o setor.

Para melhor compreendermos a regulação inglesa atualmente, é relevante destacar o histórico do setor nesse país. Em 1973, passara esse por uma reforma que procurava integrar a prestação dos referidos serviços públicos, antes explorados de forma descentralizada por inúmeros prestadores regionais e locais, públicos e privados. Já na década de 60, como relatam Amparo e Calmon (2000), era nítido o movimento centralizador, com vistas a se obter ganhos de escala, aprimorar a gestão dos recursos hídricos compatibilizando-os com as bacias hidrográficas e reduzir a fragmentação que então marcava o setor no país: os mais de mil operadores da década de 50 se tornariam centenas na década seguinte.

A reforma de 1973 procurava consolidar essa tendência, tendo por marco a aprovação, neste ano, do Water Act. Através dele, criavam-se nove companhias regionais de água na Inglaterra e uma no País de Gales, ficando essas entidades - conhecidas como Regional Water Authorities - responsáveis pela gestão e controle de recursos hídricos em suas jurisdições, que correspondiam a uma bacia hidrográfica, bem como pela prestação dos serviços de água e esgoto.

Concomitantemente, o governo central, que controlaria essas novas entidades, ganhava poder em face das autoridades locais, que apenas teriam participação nos conselhos das entidades regionais. Essa participação foi, contudo, fulminada com o Water Act de 1983, quando o Governo conservador britânico fortaleceria o caráter centralizado do setor sob a justificativa de introduzir novas práticas comerciais que viabilizassem economicamente as companhias regionais. A idéia subjacente a essa medida era a de que, ao se alijarem as autoridades locais da gestão do saneamento, as companhias regionais fortaleceriam sua autonomia gerencial, ficando libertas de influências políticas locais.

A despeito da centralização do controle dos órgãos responsáveis pela gestão dos serviços nos operadores regionais, a reforma dos anos 70 preservou as prerrogativas dos 29 operadores privados (Statutory Water Companies) que continuariam 
a ser responsáveis pelo suprimento de água em considerável proporção dos domicílios ingleses. Esse foi o marco institucional do setor até meados dos anos 80 , quando o governo britânico poria na agenda política a privatização das autoridades regionais, que sofriam, então, com as restrições fiscais que à época se impunham sobre o Estado e com as medidas antiinflacionárias que lhes vedavam o aumento de tarifas necessário para viabilizar novos investimentos.

A primeira proposta de privatização das operadoras regionais seria formalizada em 1986, com a apresentação de projeto de lei que as transformava em Public Limited Companies - PLC, cujos ativos seriam alienados na bolsa de valores para a iniciativa privada, conservando-se as responsabilidades dessas operadoras sobre as suas jurisdições. A essa proposta, em seguida retirada, reagiram grupos ambientais, empresariais, de consumidores e a oposição trabalhista, superados, contudo, pela ratificação popular do programa conservador nas eleições de 1987, que reafirmara o propósito de privatizá-las. O novo projeto de privatização apresentado após as eleições mantinha as bases do projeto anterior, acatando, contudo, crítica dos grupos ambientais, ao excluir do controle dos entes privatizados a preservação dos rios e da poluição - que ficaria a cargo da National Rivers Authority - NRA, que seria criada para absorver essas funções posteriormente fundida com a Her Majesty Inspectorate of Pollution - HMIP, para dar origem à Environment Agency. Também seria criada a Drinking Water Inspectorate, responsável pela fiscalização da qualidade da água fornecida aos usuários dos serviços de saneamento.

Outra inovação institucional seria a criação de um ente regulador independente para o setor, o Water Services Regulation Authority - OFWAT, responsável pela regulação econômica que abrangia a proteção dos usuários e da competição, a busca pela eficiência e a fiscalização dos instruments of appointment que disciplinavam a relação entre as operadoras privadas e o governo inglês, representado pela Secretaria de Estado para o Meio Ambiente. Também as 29 Statutory Water Companies passariam incólumes pela reforma,

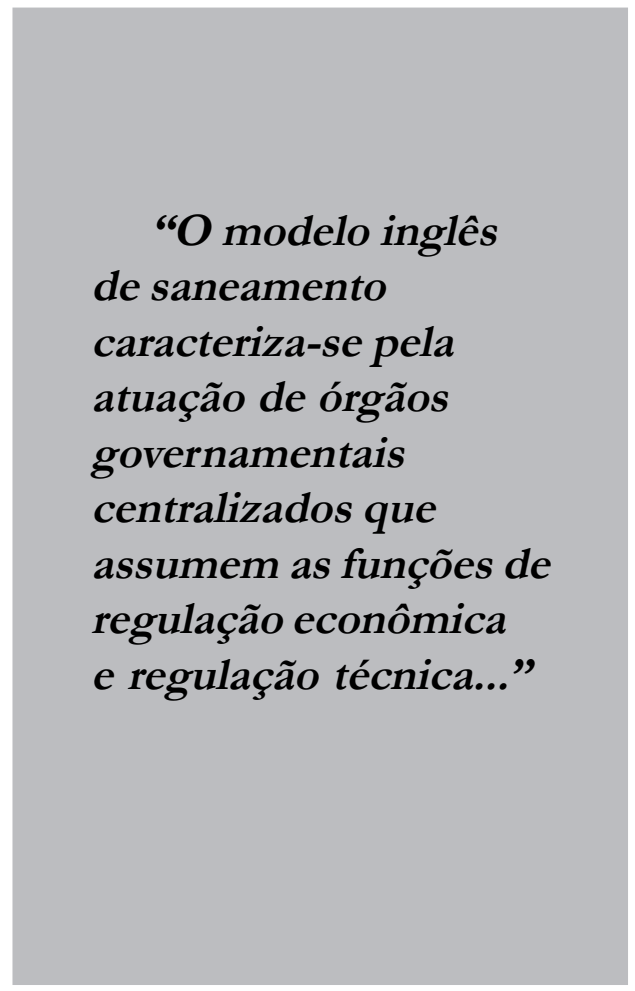

recebendo autorização para permanecer em operação sob o novo modelo.

Dessa forma, o modelo inglês de saneamento, denominado "regulação por agência” (CORRALES, 1998), caracteriza-se pela atuação de órgãos governamentais centralizados que assumem as funções de regulação econômica (OFWAT) e regulação técnica (secretarias de Estado, Environment Agency, Drinking Water Inspectorate), respondendo a 
primeira pela regulação de tarifas, defesa do consumidor, promoção de eficiência e competição; e as segundas, pela definição de padrões de qualidade, fiscalização de normas ambientais e monitoramento da qualidade da água potável produzida, em especial, para fins de atendimento às normativas da Comissão Européia, crescentemente restritivas na década de 90 .

Como instrumentos para induzir a eficiência e competitividade do setor, o modelo inglês adotou dois que são marcadamente associados à experiência inglesa de regulação: o price-cap, segundo o qual o preço da tarifa é definido no momento da compra dos ativos, sendo reajustado por um índice de preço (Retail Index Price - RIP), de que se deduz um fator de produtividade $(\mathrm{X})$ e, se for o caso, se acresce $(\mathrm{Y})$ um fator representativo do adiantamento de investimentos; e o yardstick competition, ou competição administrada, pelo qual o OFWAT fiscaliza os parâmetros de eficiência de um operador em comparação com outros operadores, reproduzindo, assim, um ambiente competitivo num monopólio natural.

O pressuposto básico dessa combinação entre price-cap e competição administrada era que uma regulação capaz de introduzir os incentivos de mercado faltantes num monopólio natural garantiria mais incentivos do que a ordenação legal do ente regulador (BAKER, 2003) e evitaria os altos custos transacionais requeridos para se monitorar permanentemente os custos do regulado - o que ocorria no regime de cost-plus, no qual era assegurado ao regulado uma taxa de retorno sobre os custos permanentemente monitorados.

O novo marco regulatório do setor seria aprovado em julho de 1989, através do Water Act, viabilizando, em seguida, a alienação dos ativos das 10 operadoras regionais para boldings privadas em novembro de 1989.

O desenho do modelo inglês foi influenciado, então, pelo propósito de atrair novos investidores para um setor que fora submetido a fortes restrições decorrentes das políticas monetária e fiscal do governo. Essa preocupação central do modelo regulatório provocaria, nos anos seguintes, severas críticas decorrentes dos sucessivos aumentos de tarifa acima da inflação ${ }^{10}$, dos lucros obtidos pelas operadoras privadas num ambiente econômico que melhorara substancialmente na década de 90 e pelo saneamento promovido pelo governo antes de alienar as empresas, em condições supostamente vantajosas para os particulares.

O fato é que o governo respondeu a essas críticas com a antecipação do processo de revisão tarifária para 1995 (quando inicialmente se previra a primeira revisão para 1999), culminando com a redução do percentual de reajuste admitido acima da inflação de $5 \%$ para $1 \%$. Nessa ocasião, foram incrementadas as obrigações de investimentos das operadoras privadas. Ambas as medidas tinham por pressuposto que essas empresas deveriam compartilhar com os consumidores nos anos seguintes os ganhos extraordinários do período 89-95.

Curiosamente, como nota Baker (2003), a regulação por incentivos por meio do price-cap, que superaria o modelo cost-plus por induzir maior eficiência e reduzir os custos com o monitoramento das informações de custos das operadoras, terminou por demandar o mesmo tipo de processo de revisão de preços do regime cost-plus, com uma intervenção do regulador bem maior do que originariamente se previa; o regime, pois, sucumbira de início: em vez da aplicação da fórmula de reajuste do price-cap, a primeira 
revisão alterou as regras, diminuiu a taxa de retorno dos operadores e ainda incrementou as suas obrigações. Em vez de regulação por incentivos ocorrera uma re-regulação em face da má-adaptação do price-cap.

$\mathrm{Na}$ revisão periódica de 1999, a OFWAT iria ainda mais além, reduzindo em 2\%, em média, por ano, até 2004, o preço das tarifas das operadoras, a ponto de algumas delas oferecerem aos consumidores, no período, a aquisição da propriedade dos ativos, conservando apenas para si a gestão (idem). Em 2004, na revisão periódica subseqüente, a OFWAT autorizaria um novo aumento, desta vez moderado, de preços (CAVE E ERbeta, 2006).

Outro aspecto de preocupação no modelo inglês foi o processo de concentração das Statutory Water Companies, e até mesmo das companhias regionais de água e esgoto. As primeiras, em especial, diante de sucessivas fusões e aquisições iniciadas já em 1989, passaram de 29, em 1989, para 15, em 2007. Para agravar, parte considerável dos operadores é controlada pelas francesas Lyonnaise des Eaux e Générale des Eaux, duas multinacionais atuantes no mercado internacional de saneamento (Amparo e Calmon, 2000).

Ao risco representado pela concentração o governo britânico respondeu com a edição de sucessivas normas que visavam a impedir o uso abusivo de poder econômico pelas operadoras.

Inicialmente, o governo fez uso de licenças locais (inset appointments) que, previstas no Water Act de 1989 apenas para áreas rurais não abastecidas pelos operadores existentes, foram adotadas sem essas limitações a partir de 1995. Consistem elas na autorização para que operadores atuem em áreas isoladas da jurisdição de outros operadores, contestando seus monopólios.

Mais recentemente, destacam-se o Competition Act, de 1998, que dava poderes para que o OFWAT investigasse condutas anticompetitivas; e o Water Supply Licensing, criado pelo Water Act de 2003, que entrou em vigor em 2005, com o objetivo de abrir uma pequena parte do mercado de abastecimento de água para a competição; segundo o OFWAT (2007), aproximadamente 2.200 consumidores entre 23,4 milhões são, hoje, elegíveis para esse regime mais competitivo.

Apesar desses esforços, o OFWAT (2007) reconhece que, mesmo após a edição do Water Supply Licensing, pouco progresso foi alcançado, lançando propostas para aumentar a competitividade do setor nos próximos anos.

A despeito das críticas, os investimentos em saneamento na Inglaterra cresceram substancialmente após as privatizações, superando rapidamente a média de investimentos da década de 80. Estimase que, até 2010 , terão sido investidos 70 bilhões de libras no setor, desde 1989 (OFWAT, 2007).

\section{A regulação do saneamento no Brasil}

A indefinição característica da regulação dos serviços públicos de saneamento no Brasil é conseqüência do conflito federativo sobre a titularidade dos referidos serviços. A Constituição Federal de 1988 atribuiu aos municípios, em seu art. 30, inciso $\mathrm{V}$, a competência para prestar os serviços públicos de interesse local; por seu turno, o art. $25, \S 3^{\circ}$, previu que lei complementar estadual disporia sobre a criação de regiões metropolitanas para organização de serviços públicos integrados. Desses 
dispositivos nasce o imbróglio que há mais de 15 anos paralisa inúmeras tentativas de implantação de um modelo regulatório.

Isso ocorre porque os serviços de saneamento são compostos por inúmeras atividades concatenadas - captação, adução, tratamento e distribuição de água; coleta, tratamento e disposição final do esgoto freqüentemente integradas, especialmente nas regiões conurbadas, em razão de os estados reclamarem sua competência estadual para organizar os serviços de saneamento em regiões metropolitanas, por força da preponderância do interesse metropolitano sobre o interesse local.

A definição da competência constitucional em áreas metropolitanas, não enfrentada pela Lei Federal no 11.445/2007, que dispôs sobre as diretrizes nacionais para o saneamento básico - que disciplina o exercício da competência, mas não esclarece a titularidade dos serviços, de natureza constitucional -, aparentemente ficará a cargo do Supremo Tribunal Federal, ao julgar as Ações Diretas de Inconstitucionalidade $\mathrm{n}^{\circ} 1.842 / \mathrm{RJ}$ e $\mathrm{n}^{\circ} 2.077 / \mathrm{BA}^{11}$.

É fato, ainda, que a herança do modelo Planasa, instituído durante os anos 70 pelo regime militar e marcado pela prestação dos serviços através de companhias estaduais de saneamento - ainda predominante a despeito de seu fim formal demarca as posições conflitantes entre municípios interessados em reassumir sua competência, sobretudo quando é viável economicamente a exploração dos serviços, e estados resistentes em ceder aos municípios o poder de organizar e prestar serviços há tanto tempo.

Conforme relata Sanchez (2001), o enfraquecimento do regime militar no início da década de 80, que dava sustentação aos "anéis burocráticos" que uniam a Associação Brasileira de Engenharia
Sanitária e Ambiental (Abes) e as Companhias Estaduais de Saneamento (CESBs), levou ao surgimento de dois novos componentes organizados no setor: a Associação Nacional dos Serviços Municipais de Saneamento (Assemae) ${ }^{12}$ - formada principalmente pela alta burocracia dos serviços de saneamento dos municípios que não havia aderido às CESBs - e os sindicatos, em especial a Federação dos Trabalhadores Urbanitários (FNU)".

Dessa forma, para compreendermos o modelo de organização dos serviços de saneamento no Brasil, inclusive sua disciplina a partir da Lei Federal $n^{\circ} 11.445 /$ 2007, é imprescindível passarmos pela história que o precede, cujo legado está presente nos desafios a se enfrentar.

Assim como outros setores de utilidade pública, como rodovias e energia, o setor de saneamento é inaugurado no Brasil no fim do século XIX, com obras em São Paulo, no Rio de Janeiro e em Recife, através da concessão da prerrogativa de explorar os serviços outorgada pela União - então no exercício, de fato, do poder concedente - para empresas estrangeiras.

Nesse caminho foram prestados os serviços até a década de 30 do século XX, quando o Governo Vargas nacionaliza as concessionárias e edita o Código de Águas em 1934, que viria a disciplinar o uso de recursos hídricos no território nacional, inclusive sua concessão.

Encerrado o período autoritário de Vargas, as décadas de 40 e 50 seriam marcadas pelo processo de descentralização dos serviços para estados e municípios, sob o suporte do Serviço Especial de Saúde Pública do Ministério da Saúde - SESP, ulteriormente transformado na Fundação Nacional de Saúde - Funasa.

Finalmente, é na década de 60, com o novo processo centralizador empreendido 
pelo regime militar, que se desenharia o quadro que até hoje prevalece no setor, mesmo após seu fim formal.

Primeiramente, a reforma tributária de 1967 concentraria receitas na União Federal, conferindo-lhe a capacidade para induzir a adesão de municípios e estados aos arranjos por ela propostos; depois, foram criados o Banco Nacional de Habitação - BNH, o Fundo de Garantia por Tempo de Serviço - FGTS e o Sistema de Financiamento de Saneamento - SFS, estruturando-se, dessa forma, as instituições que coordenariam e financiariam a prestação dos serviços de saneamento nas décadas seguintes.

Isto feito, a União Federal criou por intermédio do Decreto-Lei no 649/1969 o Plano Nacional de Saneamento Planasa. Pela adesão ao Plano que lhes viabilizaria financiar os investimentos, os municípios, considerados titulares dos serviços, delegariam concessões de serviços públicos às companhias estaduais de saneamento então criadas. $\mathrm{O}$ afastamento dos municípios da regulação dos serviços também foi marcante no Planasa, reproduzindo-se ainda hoje nos locais onde as CESBs mantêm suas concessões sem qualquer regulação municipal e, quando muito, reguladas de maneira tímida por agências reguladoras estaduais.

As CESBs prestariam os serviços em jurisdição estadual, utilizando-se de subsídios cruzados para, em tese, possibilitar a prestação dos serviços em áreas cuja viabilidade econômico-financeira não estivesse assegurada, com cobrança de "tarifas sociais"; dessa forma, os recursos hauridos com municípios superavitários permitiriam a expansão dos serviços em regiões deficitárias.

A despeito das críticas que viria a enfrentar nas décadas seguintes, o Planasa obteve relativo sucesso até o início da década de 80, quando as crises da dívida em particular e do Estado em geral comprimiriam os recursos disponíveis para investimentos em infra-estrutura.

De acordo com Seroa da Motta (2004), apesar do inegável crescimento da cobertura, esta não foi incrementada de forma linear entre serviços, regiões e faixas demográficas. Os serviços de abastecimento de água foram bem mais

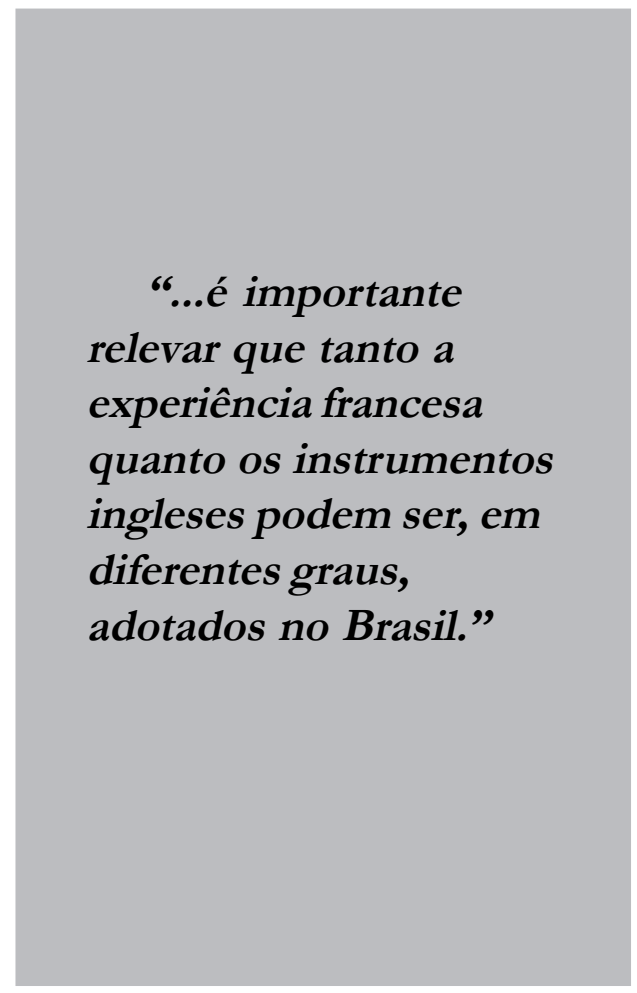

expandidos do que os de esgotamento sanitário, o Sudeste obteve maior êxito e os economicamente mais ricos também foram mais beneficiados.

Além dos aspectos gerais que viriam a reduzir os investimentos em infra-estrutura na década de 80 - crise fiscal, manipulação política de tarifas, tentativa de controle inflacionário, etc. -, que ficam claramente diagnosticados em publicação recente do 
Banco Mundial (2007), o modelo Planasa foi afetado, ainda, pela ineficiência operacional das $\mathrm{CESBs}^{13}$, pela descapitalização do FGTS nos anos 80 (em decorrência da crise econômica) e pela extinção do BNH (MARINHO, 2006).

$\mathrm{O}$ enfraquecimento do modelo seria consolidado com a Constituição Federal de 1988, que descentralizaria recursos especialmente para os municípios, deixando, contudo, de definir com clareza a competência constitucional para a organização dos serviços em áreas metropolitanas, como já exposto. Assim, o fim formal do Planasa deu-se em 1990, por meio da expedição da Resolução no 02 de 28/02/1990 pelo Conselho Curador do FGTS.

O fim formal, entretanto, não foi convertido em desestruturação absoluta do modelo Planasa. Nesse período de mais de 15 anos após a promulgação da Constituição Federal, o vazio regulatório nacional, políticas federais sem continuidade, ausência de consenso sobre projetos de lei, diferentes estratégias das $\mathrm{CESBs}^{14}$ e dos municípios e disputas judiciais entre eles não foram suficientes para a redefinição do setor de saneamento no Brasil, ainda predominantemente reprodutor das estruturas institucionais do Planasa, sem existência de regulação, de fato, das atividades prestadas pelas $\mathrm{CESBs}^{15}$ "sub-regulado" ou "auto-regulado", segundo as expressões de Turolla (2004) ${ }^{16}$. Seroa da Motta reporta que mais de $80 \%$ da população permanece sendo atendida sob o arranjo institucional do Planasa, com uma minoria de municípios atendidos por entidades públicas ou privadas e, ainda, dois casos de prestação regionalizada (Região dos Lagos/RJ e Juturnaíba/RJ).

Entre os municípios que reassumiram sua competência, a literatura registra experiências incipientes e cercadas de problemas, como as de Ribeirão Preto (FERreira, 2005) e Limeira (World BANK, 2007). Ainda assim, Seroa da Motta e Moreira (2004) constataram maior eficiência e menores preços nas experiências municipais em comparação com as operadoras estaduais, compreendendo tanto "municípios muito pequenos, com menos de 50 mil habitantes, até os grandes, com mais de 1 milhão".

Contudo, o movimento de municípios mais populosos e com maior potencialidade econômico-financeira evidentemente põe em xeque o modelo Planasa, sendo duvidosa a possibilidade de convivência da primeira tendência com o segundo arranjo, dado que este último pressupõe uma estrutura de subsídios cruzados com a transferência de recursos de municípios superavitários para aqueles deficitários. A saída dos municípios metropolitanos, que deverá se acentuar caso confirmada a tendência do STF sobre a competência dos serviços nas regiões conurbadas, impõe a revisão do modelo institucional do setor, em especial do uso de subsídios cruzados, objeto de seguidas críticas $^{17}$ (SEROA DA MotTA e Moreira, 2004).

Apesar dos principais desafios ressaltados - indefinição de competência, ausência de regulação, ineficiência operacional e subsídios cruzados - as recentes leis de parcerias público-privadas (lei federal no 11.079/2004), dos consórcios públicos (lei federal $n^{\circ} 11.107 / 2005$ ) e do saneamento básico (lei federal $\left.\mathrm{n}^{\circ} 11.445 / 2007\right)$ dão um alento ao disciplinar novos instrumentos de associação entre os entes da federação, entre estes e as empresas privadas, além de impor a criação de estruturas regulatórias para o setor, disciplinando o exercício da titularidade há tanto vítima do vazio institucional.

Tanto as PPPs (Turolla, 2004) quanto os consórcios públicos vêm sendo 
mencionados freqüentemente como instrumentos com aplicabilidade para o setor de saneamento. Destaque-se, a propósito, que a PPP contratada pela Empresa Baiana de Saneamento em 2006 destina-se à construção e operação de um emissário submarino (SHINOHARA, 2006). Já os consórcios públicos instrumentalizam a gestão associada dos serviços públicos, a prestação regionalizada e, até mesmo, permitem a contratação pelos municípios titulares, com dispensa de licitação, das companhias estaduais de saneamento, abrindo, assim, espaço para que as CESBs permaneçam prestando os serviços quando extintos seus prazos de concessão, desde que em um contexto de gestão dos serviços com amparo em um consórcio público que reúna os municípios outorgantes e o estado controlador da CESB.

A Lei do Saneamento resulta de um acordo entre representantes de estados e municípios. Sua aprovação, após 15 anos de tramitação de projetos de lei (sem sucesso), de diferentes naturezas no Congresso, decorreu da reunião dos Projetos de Lei $n^{\circ} 5.296 / 2005$ e $n^{\circ} 155 / 2005$ (o primeiro apresentado pela União; o segundo, pelo senador Gérson Camata) e abre perspectivas para a definição de novos modelos pelos titulares dos serviços.

O referido diploma legislativo não representa um marco regulatório - o que deve ser desenhado pelos titulares dos serviços de acordo com os instrumentos a eles disponíveis -, mas, sim, uma disciplina de diretrizes gerais, tendo como principal mérito obrigar que os titulares dos serviços caminhem do atual modelo "sub-regulado" ou "auto-regulado" para uma efetiva regulação.

Nesse sentido, destacamos abaixo os principais aspectos da Lei do Saneamento que devem orientar a política regulatória do setor nos próximos anos:
1) Os recursos hídricos não integram os serviços de saneamento básico, estando sujeitos a outorga do direito de uso $\left(\operatorname{art.} 4^{\circ}\right)$, mas devem ser geridos em integração - que a lei enfatiza -, reunindo política de saneamento, de meio-ambiente e de gestão de recursos hídricos (art. $2^{\circ} \mathrm{VI}$ c/c art. 43 a 46). Ainda, os planos de saneamento básico devem ser compatíveis com os planos das bacias hidrográficas em que estão inseridos (art. 19, \ $3^{\circ}$ ) e a União Federal deve adotar as bacias hidrográficas como unidades de referência para planejamento de suas ações (art. 48, X), seguindo assim os modelos francês e inglês de gestão de recursos hídricos por bacias;

2) Os titulares são autorizados a delegar a organização, a regulação, a fiscalização e a prestação dos serviços, mas obrigados a formular sua política de saneamento, inclusive definindo o ente regulador $\left(\operatorname{art} .8^{\circ}\right)$. Mas a delegação dos serviços a ente que não integra a administração do ente titular depende de contrato (excetuadas associações, cooperativas e convênios celebrados antes de 06/04/2005, quando aprovada a Lei dos Consórcios Públicos) - art. 10;

3) Reitere-se que a Lei dos Consórcios Públicos acresceu o inciso XXVI ao art. 24 da Lei de Licitações, permitindo a dispensa de licitação para celebração de contrato de programa com ente da Federação ou de sua administração indireta, para prestação de serviços públicos, conforme autorizado em consórcio ou em convênio de cooperação, abrindo, assim, espaço para que as CESBs sejam contratadas pelos titulares dos serviços dentro de um contrato de programa;

4) Se concedidos os serviços, as normas regulatórias devem incluir (art. 11, $\int 2^{\circ}$ ): autorização para a contratação dos serviços; metas progressivas e graduais de 
expansão dos serviços, da qualidade, da eficiência e do uso racional da água, da energia e de outros recursos naturais; prioridades de ação, compatíveis com as metas estabelecidas; condições de sustentabilidade e equilíbrio econômico financeiro da prestação dos serviços, em regime de eficiência, incluindo: sistema de cobrança e a composição de taxas e tarifas; sistemática de reajustes e de revisões de taxas e tarifas; política de subsídios; mecanismos de controle social; hipóteses de intervenção e de retomada dos serviços;

5) A Lei prevê a desintegração vertical dos serviços, com a presença de prestadores de atividades interdependentes, cuja relação será regida por contrato (art. 12). Neste caso, o contratante que tem relação com o usuário é obrigado a destacar, nos documentos de cobrança, o valor da remuneração dos serviços prestados pelo contratado e de realizar a respectiva arrecadação e entrega dos valores arrecadados $\left(\operatorname{art.12}, \int 3^{\circ}\right)$;

6) Os titulares podem instituir fundos para universalização, que podem servir como garantias para operações de créditos com esse fim (art. 13);

7) É disciplinada a prestação regionalizada, com as seguintes características (art. 14): um único prestador do serviço para vários municípios, contíguos ou não; uniformidade de fiscalização e regulação dos serviços, inclusive de sua remuneração; compatibilidade de planejamento (não necessariamente há um plano único - art. 17). A regulação, nesse caso, pode ser feita por órgão/ente de unidade da Federação ou por consórcio público (art. 15), podendo ser feita por órgão, autarquia, fundação de direito público, consórcio público, empresa pública, sociedade de economia mista (estadual ou municipal) ou empresa privada (art. 16);
8) A prestação de serviços públicos de saneamento básico observará planos, que poderão ser específicos para cada serviço (art. 19) e editados pelos titulares, podendo ser elaborados com base em estudos fornecidos pelos prestadores de cada serviço e devendo ser revistos na periodicidade mínima de 4 anos, antes dos PPAs (art. 19, \ $4^{\circ}$ ). Os planos deverão ser compatíveis com os planos das bacias hidrográficas em que estiverem inseridos (art. 19, \ $3^{\circ}$ ) e a delegação de serviço de saneamento básico não dispensa o cumprimento pelo prestador do respectivo plano de saneamento básico em vigor à época da delegação (art. 19, $\int 6^{\circ}$ ). Perceba-se que foi vetado o art. 20, que classificava os planos como mera "referência" para os prestadores.

9) As normas que obrigam a criação do ente regulador seguem o padrão convencionado de agências reguladoras (independência, transparência, publicidade, direito dos usuários, poder normativo etc.) - art. 21, admitindo-se a delegação da função regulatória a qualquer entidade dentro dos limites do estado do titular art. $23, \Omega 1^{\circ}$, o que pode tornar lícita a atividade reguladora de agências estaduais, hoje exercida de maneira precária;

10) Em relação a tarifas, deixa-se clara a possibilidade de subsídios tarifários e não tarifários para usuários e localidades (art.31), podendo ser diretos (usuário) ou indiretos (prestador); tarifários ou fiscais; internos (titular) ou entre localidades (prestação regionalizada).

11) Há previsão de reajuste (na forma da lei) e revisões tarifárias (ordinárias e extraordinárias - fatos não previstos no contrato, fora do controle do prestador) arts. 37 e 38 .

12) A Lei prevê compartilhamento de ganhos/fatores de produtividade (art. $38, \int 2^{\circ}$ ) e competição comparativa entre 
prestadores dos mesmos serviços em outras jurisdições (art. 38, $₫ 3^{\circ}$ ), o que pode aproximar a regulação do modelo inglês, no uso de mecanismos como price cap e yardstick competition;

13) Prevê-se a possibilidade de suspensão no caso de inadimplência, mediante prévia notificação (mínimo de 30 dias) - com exceções para estabelecimento de saúde, de educação, de internação coletiva de pessoas e usuários de baixa renda (art. 40);

14) Os investimentos em bens reversíveis se tornam créditos, que poderão ser objeto de garantia para investimentos no objeto contratual (art. 42) - as leis de concessões e PPPs já previam a possibilidade de cessão de recebíveis oriundos da prestação de serviços públicos delegados; mas, nesse caso, a Lei de Saneamento vai além, permitindo que se considerem como créditos os investimentos indenizáveis em bens reversíveis.

\section{Conclusão}

A comparação empreendida no presente trabalho evidencia, primeiramente, o paralelo existente entre dois modelos de regulação considerados polares (Corrales, 1998), quais sejam, a "regulação por contrato" francesa e a "regulação por agência" inglesa.

Destaquemos que há, entre esses dois pólos, um clássico debate na literatura sobre regulação. A "regulação por contrato" recebeu destaque a partir do embate entre Demsetz (1968) e Posner (1970), de um lado, e Williamson (1976) e Goldberg (1976), de outro. Os dois primeiros, em crítica ao modelo de "regulação por agência" americano, argüiram que a concorrência pelo mercado de utilidades públicas com subseqüente celebração de contrato seria suficiente para impedir preços de monopólio; no que foram contestados pelos dois últimos, para os quais custos de transação exposte a ausência de concorrência ao fim do contrato poderiam dissipar os potenciais ganhos de eficiência que a concorrência pelo contrato potencializaria.

Nesse contexto controverso na literatura a Inglaterra, no transcorrer dos anos 80, desenvolveu instrumentos regulatórios que procuravam mitigar os males apontados na regulação por agência americana, como o price-cap e o yardstick competition. Os últimos relatos da OFWAT (2007), o recente estudo de Guasch (2004) sobre os contratos no regime price-cap na América Latina e o próprio desenrolar do modelo inglês, quando o price-cap foi flexibilizado diante dos lucros considerados exorbitantes das operadoras no início da década (BAKER, 2003), demonstram que tampouco esta é uma solução perfeita. As autoridades públicas francesas aparentemente conseguem dotar seus contratos de maior flexibilidade, mas à custa de um processo licitatório que inclui negociações pouco transparentes. Nesse aspecto a literatura aponta um trade-off: contratos negociados e flexíveis têm maior potencial de adaptação a contingências futuras, reduzindo custos de transação, mas são menos indutores de eficiência do que contratos rígidos no modelo price-cap (BAJARI e TAdelis, 2001).

Se em ambos os casos persistem desafios a serem enfrentados, o Brasil encontra-se numa etapa ainda mais precária, na qual sequer as principais dificuldades que o desenho regulatório pressupõe foram enfrentadas, diante de um penoso conflito federativo. Adaptando o quadro de Turolla e Ohira (2007), apresentamos comparação entre os três países: 


\begin{tabular}{|c|c|c|c|}
\hline & França & Inglaterra & Brasil \\
\hline Origem do modelo & Década de 20 & Década de 80 & Década de 70 \\
\hline $\begin{array}{l}\text { Configuração } \\
\text { administrativa }\end{array}$ & Local & $\begin{array}{l}\text { Regulação nacional } \\
\text { e operação regional } \\
\text { (bacias) }\end{array}$ & $\begin{array}{l}\text { Estadual (CESB's) e } \\
\text { municipal (municípios que } \\
\text { retomaram concessões) }\end{array}$ \\
\hline Tipo de regulação & Por processos & $\begin{array}{l}\text { Por agência } \\
\text { (price-cap) }\end{array}$ & $\begin{array}{l}\text { Auto-regulação (CESBs) ou } \\
\text { Agências estaduais; no caso } \\
\text { dos municípios, por contrato } \\
\text { ou prestação direta }\end{array}$ \\
\hline $\begin{array}{l}\text { Instrumento da } \\
\text { regulação }\end{array}$ & $\begin{array}{l}\text { Contrato e base } \\
\text { legal }\end{array}$ & Agência & $\begin{array}{l}\text { Inexistente (CESBs), } \\
\text { prestação direta ou contrato } \\
\text { (municípios) }\end{array}$ \\
\hline Propriedade dos ativos & Pública & Privada & Pública \\
\hline $\begin{array}{l}\text { Responsabilidade da } \\
\text { gestão }\end{array}$ & Privada & Privada & $\begin{array}{l}\text { Pública ou privada } \\
\text { (concessões municipais) }\end{array}$ \\
\hline $\begin{array}{l}\text { Repartição das } \\
\text { responsabilidades e } \\
\text { riscos }\end{array}$ & $\begin{array}{l}\text { Varia com o } \\
\text { contrato }\end{array}$ & Privado & $\begin{array}{l}\text { Público (CESBs e municípios } \\
\text { com prestadores diretos) ou } \\
\text { privada (concessões } \\
\text { municipais) }\end{array}$ \\
\hline Seleção do operador & $\begin{array}{l}\text { Leilão (competição } \\
\text { pelo mercado) }\end{array}$ & $\begin{array}{l}\text { Compra do } \\
\text { controle acionário } \\
\text { (take over) }\end{array}$ & $\begin{array}{l}\text { Sem licitação (CESBs), } \\
\text { licitação (concessões } \\
\text { municipais) ou prestação } \\
\text { direta municipal }\end{array}$ \\
\hline $\begin{array}{l}\text { Participação de } \\
\text { empresas privadas }\end{array}$ & $\begin{array}{l}\text { Aproximadamente } \\
80 \%\end{array}$ & Total & Concessões municipais \\
\hline
\end{tabular}

Adaptação dos quadros de Turolla e Ohina (2007), com complemento do autor

O histórico do setor de saneamento no País combinado com as características do federalismo brasileiro, em especial a repartição de competências da Constituição Federal de 1988, assegura que não se pode imaginar que o Brasil possa adotar este ou aquele modelo integralmente. Mas é também importante relevar que tanto a experiência francesa, composta de inúmeros arranjos entre parceiros públicos e privados de forma descentralizada quanto os instrumentos ingleses para tentar superar as dificuldades inerentes a um monopólio natural, podem ser, em diferentes graus, adotados no País. Recentes marcos legais como as Leis das
PPPs e dos Consórcios Públicos abriram oportunidades para tanto.

Nesse ponto, a Lei do Saneamento Básico é meritória por obrigar os entes federativos a fazerem escolhas, construindo planos e marcos regulatórios. Sem dúvida, um primeiro passo que contribui para a superação da "sub-regulação", apontada por Turolla (2002), por uma efetiva regulação, cujos desafios podem ser mais bem compreendidos com a análise dos modelos de regulação francês e inglês. Essa é a contribuição que pretendemos oferecer.

(Artigo recebido em abril de 2008. Versão final em setembro de 2008). 


\section{Notas}

${ }^{1}$ Segundo Ferreira (2005): "Na provisão de serviços de água e esgotos, uma parte significativa dos custos está justamente na construção e manutenção da infra-estrutura de adução e distribuição de água e coleta e transporte de esgoto, que permanecerá, mesmo em uma estrutura desintegrada verticalmente, com traços de monopólio natural'". A experiência inglesa, como será visto, ilustra essa dificuldade.

${ }^{2}$ De acordo com o Banco Mundial, os serviços passam a ser economicamente viáveis a partir de um mercado de 40 mil habitantes. No Brasil, menos de 120 municípios têm mais de 200 mil habitantes, de forma que em várias localidades o serviço não é economicamente viável sem subsídios (não ficou clara a relação).

${ }^{3}$ Segundo Reynaud (2007), as principais diretivas da UE vigentes são a Water Framework Directive e a Urban Wastewater'Treatment Directive.

${ }^{4}$ Conforme narra Parlatore (2000), a criação das agências que disciplinam as seis bacias hidrográficas na França foi uma inovação institucional que ficaria conhecida mundialmente.

${ }^{5}$ Ménard e Saussier (2000) resumem as restrições sobre as autoridades locais como leis que definem standards de qualidade; leis que as obrigam a seguir um processo transparente de contratação; e leis que protegem o ambiente e o recurso escasso.

${ }^{6}$ É interessante notar que a doutrina jurídica brasileira não usa a expressão intuitu personae no mesmo sentido que Huet e Saussier (2003) [não está na bibliografia do artigo]. Como exemplo, vide Di Pietro (2005): "Todos os contratos para os quais a lei (de licitações) exige licitação são firmados intuitu personae, ou seja, em razão de condições pessoais do contratado, apuradas no processo de licitação". Esse entendimento não se confunde com a idéia de escolha subjetiva do órgão licitante, que é vedada pela legislação brasileira (lei federal n. 8.666/93, art. 44).

${ }^{7}$ Turolla e Ohira (2007), embora salientando que o modelo francês incentiva a eficiência "sem impor um ônus pesado ao Poder Público", assim enunciam o problema: "As grandes empresas de saneamento francesas operam em estreita ligação com as lideranças dos governos locais e centrais e mesmo entre si, sendo notórios os casos de corrupção e de colusão na competição pelos contratos e na operação dos serviços. A forte associação entre as próprias empresas pode ser exemplificada por um leilão de concessão em uma comuna, relatado por The Economist (1997), no qual o valor de cinco das seis ofertas secretas variou apenas $0,1 \%$ entre essas".

${ }^{8}$ Embora nos reportemos ao modelo inglês, é preciso salientar que o sistema implantado a partir de 1989 abrangia a Inglaterra e o País de Gales.

${ }^{9}$ Amparo e Calmon (2000) citam a privatização da Jaguar e da British Aerospace no início da década de 80, da British Telecom e da British Gas, respectivamente, em 84 e 86, e da British Airports Authority em 1987.

${ }^{10}$ Segundo as regras previstas na época da privatização, as operadoras poderiam reajustar suas tarifas no percentual de 5\% acima da inflação, com vistas a financiar os ambiciosos planos de investimentos estabelecidos.

${ }^{11}$ A primeira foi ajuizada pelo Partido Democrático Trabalhista (PDT) contra a Lei Estadual do Rio de Janeiro que criava a Região Metropolitana dos Lagos - onde hoje se exerce a gestão associada dos serviços - e atribuía ao Estado competência para a disciplina de serviços públicos na nova jurisdição; foram proferidos 3 votos, sendo 2 (ministros Nélson Jobim e Joaquim Barbosa) em favor de sua procedência e 1 (ministro Maurício Corrêa) contra. A segunda foi ingressada pelo Partido dos Trabalhadores (PT) contra a Emenda Constitucional no 01/99 à Constituição baiana, cuja edição atribuía ao Estado a competência para explorar serviços públicos em regiões metropolitanas; 
nesta foram proferidos 4 votos (ministros Ilmar Galvão, Nélson Jobim, Joaquim Barbosa e Eros Roberto Grau) pela procedência da ação e nenhum voto contra.

${ }^{12}$ Embora o modelo Planasa instituísse fortes incentivos para que os municípios delegassem os serviços às CESBs, como relata Ferreira (2005), mais de 1.000 municípios não aderiram ao Plano, especialmente no interior paulista, mas também em municípios como Volta Redonda, Juiz de Fora, Porto Alegre, Uberlândia, Uberaba e Caxias do Sul.

${ }^{13}$ A respeito da ineficiência operacional das companhias estaduais, é relevante destacar o estudo de Seroa da Motta e Moreira (2005), concluindo que "uma grande quantidade de operadores regionais nos níveis mais baixos de produtividade e também os mais altos efeitos de escala e os níveis de tarifas revelam que, nesse tipo de operador, os efeitos de escala não estão melhorando a eficiência e baixando a tarifa" e "os operadores municipais, ambos autárquicos e privados, embora heterogêneos entre si, dominam os níveis mais altos de produtividade e os mais baixos de tarifas".

${ }^{14}$ Relata Marinho (2006) que as CESBs adotaram diferentes estratégias, por exemplo: a Sabesp (São Paulo), a Sanepar (Paraná) e a Cagece (Ceará) perseguiram mudanças organizacionais e fortalecimento gerencial, destacando-se a primeira pela atuação competitiva em São Paulo (Sanchez, 2001); a Cedae (Rio de Janeiro) e a Cesan (Espírito Santo) passaram por tentativas de privatização; a Sanemat (Mato Grosso) e Cosama (Maranhão) procuraram devolver os serviços a municípios.

${ }^{15}$ A ausência de regulação é ilustrada pelos contratos de concessão vigentes entre CESBs e municípios - sucintos, sem cláusulas de fiscalização, revisão e reajuste tarifário, resolução de conflitos etc. - e na prática se traduz numa ausência de controle sobre a prestação dos serviços, como evidenciam Seroa da Motta e Moreira (2005). Quando as agências reguladoras estaduais desempenham algum papel, fazem-no de forma precária, já que não têm delegação do município para tanto, nem marco regulatório, nem contrato que oriente sua atuação.

${ }^{16}$ De acordo com Galvão Júnior e Monteiro (2006), os contratos de concessão celebrados durante o Planasa e ainda hoje vigentes eram omissos quanto à regulação e à fiscalização e tampouco fixavam metas de qualidade e de atendimento. Na prática, segundo os autores, as CESBs desde então atuam como reguladoras e reguladas.

${ }^{17}$ Para Seroa da Motta e Moreira (2005): “...os padrões de acesso a serviços de saneamento no país, os padrões de investimento e tarifário adotados no setor com largo uso de subsídios cruzados não resultaram em uma desconcentração significativa do acesso aos serviços direcionados para as áreas mais ricas das cidades. Só quando as carências se exacerbam nas áreas pobres, programas especiais e focados são desenvolvidos. Se o objetivo for realmente garantir o abastecimento mínimo de água e coleta de esgoto para os mais pobres, então há que se focar mais a aplicação de subsídios". 


\section{Referências bibliográficas}

Amparo, Paulo Pitanga do e Calmon, Katya Maria Nasiaseni. A experiência britânica de privatização do saneamento. Brasilia: Ipea, Texto para discussão n 701, 2000.

Bajari, Patrick e TAdelis, Steven. Incentives versus Transaction costs: a theory of procurement contracts. RAND Journal of economics, 32:3, 2001.

BAKER, Karen J.. From public... to mutual? Reestructuring water supply governance in England and Wales. Geoforum, 34, 2003.

Cave, Martin e Erbeta, Fabrizio. Regulation and efficiency incentives: evidence from the England and Wales Water and Sewerage Industry. Hermes, working paper 8, 2006.

Corrales, Maria Elena. La regulación en períodos de transición: el caso de los servicios de agua potable y saneamiento en América Latina. In: ¿ Que hay de nuevo en las regulaciones?: Telecomunicaciones, eletricidad y agua potable en América Latina. Argentina: EUDEBA/ CLAD, 1998.

DemseTZ, Harold. Why regulate utilities?. Journal of Law and Economics, 11:1, 1968.

Di Pietro, Maria Sylvia Zanella. Direito Administrativo. São Paulo: Atlas, 2005.

Ferreira, Fernanda Meirelles. Regulação por contrato no setor de saneamento: o caso de Ribeirão Preto. Dissertação (Mestrado em Administração Pública e Governo). Fundação Getúlio Vargas. São Paulo, 2005.

Galvão Junior, Alceu de Castro and Monteiro, Mario Augusto Parente. Analysis of concession agreements for provision of water and sewage services in Brazil. Eng. Sanit. Ambient., Oct./Dec. 2006, vol.11, no.4, p.353-361.

Goldberg, Victor. Regulation and administered contracts. The Bell Journal of Economics, 7: 2, 1976.

GuASCH, J. Luís. Granting and renegotiating infrastructure concessions: doing it right. Washington D.C.: The World Bank Institution, 2004.

Ménard, Claude e Saussier, Stéphane. Contractual choice and performance: the case of water supply in France. Revue d'Économie Industrielle, 2000

OFWAT - Water Services Regulation Authority. Outcomes of Ofwat's internal review of market competition in water sector. OFWAT, 2007.

. Report on competition inquires and complaints: 1 abril 2006 to 31 march 2007.

OFWAT, 2007.

Marinho, Maria do Socorro Japiassú. Regulação dos serviços de saneamento no Brasil (água e esgoto). Tese de doutorado apresentada no curso de desenvolvimento econômico da Universidade Federal do Paraná. Curitiba, 2006.

Parlatore, Antônio Carlos. Privatização do setor de saneamento no Brasil. In: A Privatização no Brasil: o caso dos serviços de utilidade pública. Rio de Janeiro: BNDES, 2000.

Pinheiro, A.C. e SAdDi, J. Direito, Economia e Mercados. Rio de Janeiro: Elsevier, 2005

Poldit, Christopher e BoucKAerT, Geert. Public Management Reform: a comparative analysis. Oxford: Oxford University Press, 2000. 
Posner, Richard. Cable Television: The problem of local monopoly. Rand Memorandumm, RM-6309-FF, 1970.

Reynaud, Arnauld. Social Policy and Private Sector Participation in Water Supply: the case of France. UNRISD, 2007.

SAnchez, Adolfo Oscar. A privatização do saneamento. São Paulo: São Paulo em Perspectiva, 15:1, 2001.

Sepällä, Osmo T., Hukka, Jarmo J. e Katko, Tapio. S.. Public-Private Partnershios in Water and sewerage services: privatization for profit or improvement of service and performance?. Public Works Management \& Policy, 6:1, 2001.

SERoA Da Motta, Ronaldo. As opções de marco regulatório do saneamento no Brasil. In: Salgado, Lúcia Helena e Seroa da Motta, Ronaldo. Regulação e Concorrência no Brasil: Governança, Incentivos e Eficiência. Brasília, IPEA, 2007.

. Questões regulatórias do setor de saneamento no Brasil. IPEA, Notas Técnicas 5, 2004.

SERoa da Mótta, Ronaldo e Moreira, Ájax R.B.. Eficiência e Regulação no setor de saneamento no Brasil. Rio de Janeiro: IPEA, 2004.

Shinohara, Daniel. Parcerias Público-Privadas: um estudo de casos no Brasil. Dissertação de mestrado apresentada no curso de Administração da Universidade de São Paulo. São Paulo, 2006.

Turolla, Frederico Araújo. Política de saneamento básico: avanços recentes e opções futuras de políticas públicas. Brasília: IPEA, Textos para discussão nº 922, 2002.

Turolla, Frederico Araújo e OHira, Thelma Harumi. Pontos para uma discussão sobre eficiência e regulação em saneamento. In: SAlgado, Lúcia Helena e SEROA DA MotTA, Ronaldo. Regulação e Concorrência no Brasil: Governança, Incentivos e Eficiência. Brasília, IPEA, 2007.

Turolla, Frederico Araújo, Anker, Tomas e FAria, Ricardo Ferreira, Infrastructure services in Brazil: the role of public-private partnerships (PPP) in the water \& sewerage sector. 2004. Disponível em SSRN: http://ssrn.com/abstract=616241

WorLd BANK. How to revitalize infrastructure in Brazil: public policies for better private participation. Washington D.C.: World Bank, 2007.

Williamson, Oliver. Franchise Bidding for Natural Monopolies-in General and with Respect to CATV. The Bell Journal of Economics, 7: 1, 1976. 


\section{Resumo - Resumen - Abstract}

\section{A regulação no setor de saneamento: comparação entre França, Inglaterra e Brasil}

Marcelo Bruto da Costa Correia

$\mathrm{O}$ artigo discute as características da regulação dos serviços públicos no setor de saneamento, apresentando comparativamente as formas de prestação adotadas por França, Inglaterra e Brasil - e como esses países disciplinam a participação privada no setor. Enquanto a França segue um padrão histórico de regulação marcado pelo protagonismo das autoridades locais, utilizando contratos como instrumento por excelência de disciplina dos serviços, a Inglaterra introduziu, através de ambicioso processo de privatização, marco regulatório em que agências do Governo Central são os atores principais. Ainda sem um modelo definido, o Brasil, através de inovações legais, enfrenta os desafios de atrair investimentos privados para um setor sob a presença de conflitos federativos entre estados e municípios acerca da titularidade dos referidos serviços públicos.

\section{Palavras-chave: Saneamento; regulação; serviços públicos.}

\section{La regulación de los servicios públicos em la industria de saneamiento}

Marcelo Bruto da Costa Correia

El artículo analiza las características de la regulación de los servicios públicos en la industria de saneamiento, presentando en comparación formas de provisión aprobada por Francia, Inglaterra y Brasil - y la forma en que estos países disciplinan la participación del sector privado. Mientras que Francia sigue una tendencia histórica de la regulación marcada por el papel de las autoridades locales, mediante contratos como un instrumento por excelencia de los servicios de la disciplina, Inglaterra presentó a través de ambicioso proceso de privatización, el marco normativo en el que las agencias del Gobierno Central son los principales actores. Aun sin un modelo definido, el Brasil, a través de innovaciones jurídicas, se enfrenta a los desafíos de la atracción de la inversión privada de un sector bajo la presencia de conflictos federativos entre los estados y los municipios sobre la propiedad de estos servicios públicos.

\section{Palabras clave: Saneamiento; regulación; servicios públicos}

\section{The Regulation of Public Services in the Sanitation Industry}

\section{Marcelo Bruto da Costa Correia}

The article discusses the characteristics of the regulation of public services in the sanitation industry, presenting compared ways of providing adopted by France, England and Brazil - and how these countries discipline the private sector participation. While France follows a historical pattern of regulation marked by the role of local authorities, using contracts as an instrument par excellence of the service discipline, England introduced through ambitious privatisation process, regulatory framework in which agencies of the Central Government are the main actors. Even without a model defined, Brazil, through legal innovations, faces the challenges of attracting private investment for a sector under the presence of federative conflicts between states and municipalities about the ownership of these public services.

Key words: Sanitation; regulation; public services

\footnotetext{
Marcelo Bruto da Costa Correia

Graduado em Direito e em Administração pela Universidade Federal de Pernambuco (UFPE). Mestre e doutorando em Administração Pública e Governo, pela Fundação Getúlio Vargas.

Contato: marcelobcorreia@hotmail.com
} 